\title{
An Analysis of Insectivory in Cross River Gorillas (Gorilla gorilla diehli) in the Tofala Hill Wildlife Sanctuary, Cameroon
}

\author{
Efuetlancha T. Atem \\ University of Dschang, Department of Forestry \\ Faculty of Agronomy and Agricultural Sciences (FASA) \\ P.O Box 96, Dschang, Cameroon \\ Resource Center for Environment and Sustainable Development (RCESD) \\ P.O 30 Buea, Cameroon
}

Tchamba N. Martin

University of Dschang, Department of Forestry, Faculty of Agronomy and Agricultural Sciences (FASA), P.O Box 96, Dschang, Cameroon

Enowkewan T. Allen

The Environment and Rural Development Foundation (ERuDeF)

P.O Box 189, Buea, Cameroon

Mbunya F. Nkemnyi

Resource Center for Environment and Sustainable Development (RCESD) P.O 30 Buea, Cameroon

Received: March 13, 2018 Accepted: March 30, 2018 Published: February 19, 2019 doi:10.5296/emsd.v8i2.12807

URL: https://doi.org/10.5296/emsd.v8i2.12807

\section{Abstract}

Gorillas have a wide range of food items in their diet; fruits, leaves, shoot, roots, piths, and 
insects hence are considered as generalists (Caldecott \& Ferris, 2005; Inskipp, 2005). There exists some wide dietary flexibility between gorilla species (western and eastern gorillas). The main focus of the study was investigating on Cross River gorilla (CRG) insectivory and its influence on habitat range suitability at the Tofala Hill Wildlife Sanctuary (THWS). This was based on the hypothesis that insectivory is a determinant to habitat suitability in Cross River gorillas. Reconnaissance survey conducted resulted to 115 gorilla signs recorded amongst which were 19 gorilla dung samples. CRG habitat was characterized by indirect signs recorded within various vegetation type, canopy cover, slope and elevation. This was in order to understand and relate habitat range and food availability. Insect food availability was assessed based on the number of insect/ant mount recorded along CRG trails. Data analysis included Kolmogorov sminorv normality test and non-parametric Spearman's Rho correlation test to measure relationships between variables and Kruskal-Wallis test to compare groups for significant difference. Cross tabulations were accompanied with Cramers' V-test in order to measure the level of association between 2 categorical variables most especially in cases where they were nominal. Statistical observations were discussed at the $95 \%$ Confidence Level (Alpha=0.05). Fecal analysis revealed insect foods amongst fruits (Afromomum sp., Musa sp., Marantacae sp. etc.), and leaves in THWS CRG. Results showed that insect consumption seemed to decrease with increased altitude. The weak and negative relation in number of insect parts and altitude range permits that the hypothesis of this study be accepted. Concurrently, abundance of insect parts in feces was not necessarily dependent on altitude but dependent on age, hence adopting the hypothesis that insectivory is a determinant to habitat suitability in Cross River gorillas. This study is the very first confirmation that CRGs feed on insects; Dorylus ant and Macrotermes sp. and Cubitermes sp.

Keywords: Feeding ecology, Cross River gorilla, Habitat suitability, Insect consumption

\section{Introduction}

Gorillas have a wide range of food items in their diet; fruits, leaves, shoot, roots, piths, and insects hence are considered as generalists (Caldecott \& Ferris, 2005; Inskipp, 2005). There exists some wide dietary flexibility between gorilla species (western and eastern gorillas) and their degree of frugivory has been stated to be negatively correlated to the altitude of their habitat ranges (Ganas \& Robins, 2004). Different gorillas subspecies can be arranged from frugivorous to non-frugivorous as; western lowland gorillas > eastern lowland gorillas > cross river gorillas > bwindi mountain gorillas > virunga mountain gorillas (Robbins, 2007). Fruit eating habits in gorilla also decreases almost linearly with increasing forest elevation (Stanford, 2006), as this explains fruit eating intensity to be higher in lowland gorillas.

Gorilla invertebrate consumption has been evident, including especially social insects: hymenoptera (ants, bees, honey), orthoptera (grasshoppers/crickets), coleoptera larvae (beetles) and lepidoptera (butter flies and moths) and also sometimes annelids earthworms (Yamagiwa et al., 1991, 1996). Social colony forming insects are preferred because they offer a sizeable concentrated and often sedentary biomass and/or high caloric payoff (honey) or both (McGrew, 2001). Compared to plant food the estimated average proportion of invertebrates (insects) in gorilla diet is $1 \%$ and $4 \%$ in chimpanzees (NRC, 2003). 


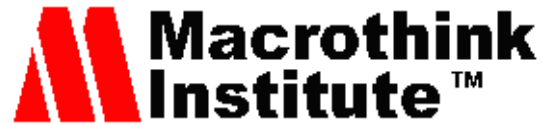

Deliberate insect-eating by mountain gorillas is considered minimal-to-negligible (Ganas \& Robbins, 2004). Tutin and Fernandez (1992) emphasized on the regular and deliberate insectivorous behavior of western lowland gorillas and suggested it to be as nutritionally important for gorillas as for chimpanzees. Gorillas obtain their insect prey using their hands by digging or scratching in soil (Nishihara \& Kuroda, 1991) or by breaking open nests (Cipolletta et al., 2007; Morgan \& Sanz, 2006). While considerable information exist on insectivory of western lowland gorillas (Remis, 1997; Tutin \& Fernandez, 1992), very little information exist on Cross River gorillas that are critically endangered and relatively understudied.

The documented frequency of western gorilla insectivory, defined as the percentage of fecal samples containing insect remains, ranges from $20 \%$ to $30 \%$ in Congo (Nishihara, 1995) and Gabon (Tutin \& Fernandez, 1992), to $>70 \%$ in Cameroon (Deblauwe et al., 2003) and Central African Republic (Remis, 1997a), suggesting that insects may represent an important component of the diet of western gorillas. There are limited reported studies on CRG feeding ecology, those of McFarland (2007) and Etiendem, (2013). The objective here was to investigate on CRG insectivorous feeding habits at the Tofala Hills Wildlife Sanctuary forest.

\section{Materials and Data Collection Techniques}

\subsection{Study Site}

The study site (THWS) located between UTM coordinates $615,000-645,000 \mathrm{~m} \mathrm{~N}$ and $560,000-612,500 \mathrm{~m}$ E. It is situated within the Wabane Sub-division in the North and Alou Sub-division in the south. It covers a total surface area of about 8087 ha (MINFOF, 2014). The area is characterised by an undulated landscape from Bechati $(365 \mathrm{~m})$ in the lower altitudes to Fossimondi $(2400 \mathrm{~m})$ in the higher altitudes. It has a number of peaks respectively at Tofala Hill (866m), around Kenyang $(980 \mathrm{~m})$ and around Old Bechati $(1,470 \mathrm{~m})$. This area forms part of the Western Mount Bamboutos that rises up to 2,740m above sea level (asl). The topographic orientation of the area directs the flow of the complex water network from north to south (Gartlan, 1989; Nkembi et al., 2008.

The forest area is mainly composed of primary (70\%) and secondary forests $(30 \%)$. The forest on the plateau is similar to lowland forest structure with a closed canopy, with limited understory but has many dense vine tangles in the mid-storey. On the steeper slopes above the plateau the canopy is more open and the diversity of trees appears lower, whilst the understory remains relatively clear (Nkembi \& Muh, 2012). The population of the Lebialem Highlands and the THWS are 35,000 and 7,000 inhabitants respectively (Etiendem et al., 2011). The forest is used by the local people for agriculture, hunting, fishing, collection of timber and non-timber forest products amongst others (Nkemnyi et al., 2013; Wright \& Priston, 2010). Ten main ethnic communities (Fossimondi, M'mock mbin, Bamumbu, Folepi, Bechati, Banti, Igumbo, Besali, Bangang, and Nkong) inhabit the land situated adjacent to the THWS. 


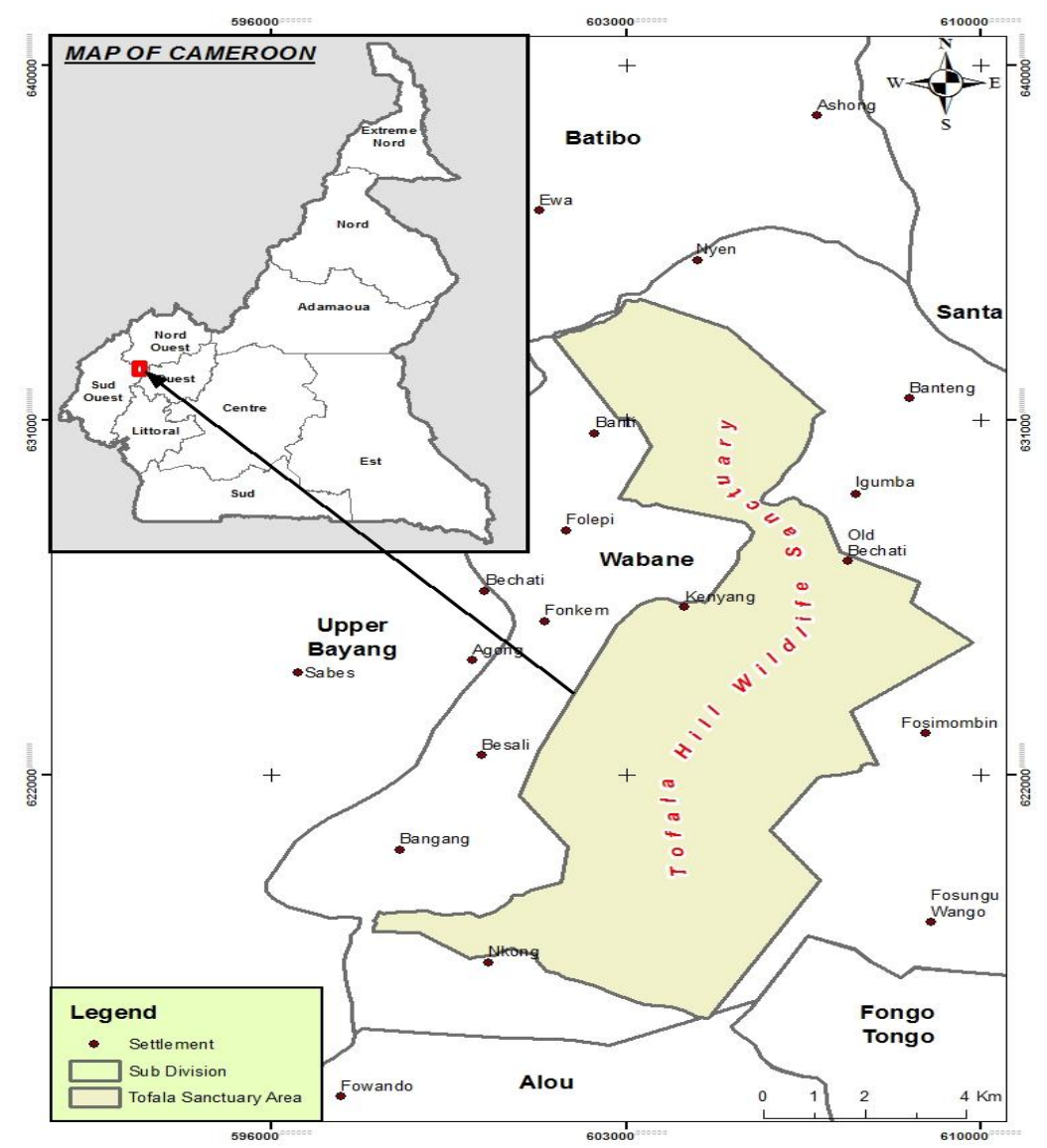

Figure 1. Location of study site

Source: This study

\subsection{Data Collections Techniques}

The fact that gorillas generally avoid humans made direct observations nearly impossible. Data collection therefore relied on indirect sampling methods in order to gain at least a broad, basic understanding of the diet of this gorilla subspecies (Doran et al., 2002, Rogers et al., 2004, Sunderland-Groves et al., 2009). Data collection made use of gloves, tubes, alcohol, $1 \mathrm{~mm}$ sieve, and sample zip bags.

Primary data was collected between August through November 2015. Guided reconnaissance surveys followed the path of least resistance, deviating not more than $40^{\circ}$ from the set compass bearing (Kuhl et al., 2008; McNeilage et al., 2006). Daily surveys were conducted following fresh gorilla feeding trails and tracks while recording all visible signs. Data collection was based on information of food remains (remnants), nest sites, as well as dung piles. An estimated $96 \mathrm{~km}$ distance was covered during 40 days of tracking making an average effort of $2.4 \mathrm{~km} /$ day. Whenever a gorilla track was identified, it was tracked all along until new signs were identified and was abandoned for a next one in case no indicatives were evident.

The mounts (insect feeding site) encountered on each daily trail during the study period were 
noted and Geographic Positioning System (GPS) positions recorded. Insect/ant mount occurrence was assessed and quantified monthly in order to estimate food availability. Fecal samples were collected and recorded as either fresh ( $<3$ days old) or recent ( $>3$ days) and were packed in plastic sachets, then coded with the species name and vegetation type. Dung diameter estimated species age class as follows: silverbacks $>7.3 \mathrm{~cm}$, adults: $5.5-7.2 \mathrm{~cm}$, Juveniles 4.0-5.4cm and infants: $<2.5 \mathrm{~cm}$ (Schaller, 1963). Insect presence was noted for various dung sizes in order to define the age class and insect dietary preference following the Tutin \& Fernandez (1993b) method. Fecal samples were washed in a running stream through a $1 \mathrm{~mm}$ sieve in order to record presence of different insect food items identified by insect parts (Tutin \& Fernandez, 1993b). Individual fecal samples were scored for the number of insect heads, legs and other parts identified in it and the percentage of samples containing all insect parts was equally calculated. Insect-eating frequency was calculated as the percentage of feces that contained insect parts, as defined by Tutin and Fernandez (1992). Geographic Positioning System (GPS) points alongside the altitude were recorded using a GPS device (Garmin 62S) in order to be able to make evaluations and deduce altitudinal influences of various parameters within the scope of the study. Insect food remains collected were stored in alcohol filled sample bottles for transportation and identification at the certified entomological units of the Institute of Agricultural Research for Development (IRAD), Ekona-Buea.

\subsection{Data Analysis}

The abundance of insect food was simply calculated by summing the number of mounts (insect feeding site) encountered on each daily trail during the study period. The quantity of insect foods was assessed through analysis of fecal matter. Insect/ant mount occurrence was assessed and quantified monthly in order to estimate food availability. The number of mounts was used to be able to calculate the density of insect food sources which served to evaluate chances of insectivory in CRG at the Tofala Hill Wildlife Sanctuary (THWS).

Fecal samples collected were recorded as either fresh ( $<3$ days old) or recent ( $>3$ days) and were packed in plastic sachets, then coded with the species name and vegetation type. Fecal bolus sizes were used to establish a relationship between species age class and insectivorous feeding habits. Dung diameter estimated species age class as follows: silverbacks $>7.3 \mathrm{~cm}$, adults: $5.5-7.2 \mathrm{~cm}$, Juveniles 4.0-5.4cm and infants: $<2.5 \mathrm{~cm}$ (Schaller, 1963). Raw data was entered into Microsoft Excel 2010, and then exported to SPSS 17.0 (IMB Inc, 2008) for exploration and analysis. Exploratory statistics constituted the where data was screened for invalid entries or codes using frequency analysis, and for outliers using Boxplot.

Variables were screened for normality using Kolmogorov-Smirnov test and it was realized that the continuous variables notably abundance of insect parts in feces, age, bolus size differed significantly from the theoretical normal distribution therefore violating the normality assumption $(\mathrm{P}<0.05)$ except in the case of altitude.

The non-parametric Spearman's Rho correlation test was then used to measure relationships between variables and Kruskal-Wallis test to compare groups for significant difference. Scale or continuous variables were described using measures of central tendency and dispersion 


\section{Ml Macrothink}

such as mean, median and range. As for the categorical variables, they were described using frequency analysis as to yield the number of counts within categories and percentage. Cross tabulation was used to distribute scores within category of a categorical variables layered by another categorical variable as to appreciate the association between them. For instance, cross tabulation could enable us to distribute species by canopy type as to see the type of canopy they prefer most or least.

Cross tabulations were accompanied by 'Cramers' $V$-test' in order to measure the level of association between 2 nominal categorical variables. All statistical procedures were presented using statistical tables and charts and were discussed at the 95\% Confidence Level (Alpha=0.05).

\section{Results}

\subsection{THWS Habitat Characterization}

A total of $115 \mathrm{CRG}$ indirect signs were recorded during the study. Based on data collected $50 \%(n=28)$ of the feeding signs recorded and 50\% $(n=7)$ of footprints were both found to be within the altitudinal range of $701-800 \mathrm{~m}$ asl. The altitudinal range of $701-800 \mathrm{~m}$ asl was that within which greater signs $(47.83 \%, \mathrm{n}=55)$ were observed in a total. Additionally, of the four tracks recorded, 3 alongside the lone playground recorded were found within a more elevated area (801-924m asl). Furthermore, indirect sign distribution with respect to altitude was equal for both primary and secondary forests (50\% each) characterized by high altitudes of between $701-800 \mathrm{~m}$ asl. Cramer's test depicts a weak $(\mathrm{v}=0.129)$ and non-significant $(\mathrm{P}>0.05, \mathrm{P}=0.419)$ level of association between altitude and vegetation type. Altitude did not influence vegetation type within which indirect CRG signs were recorded. Figure 2 below depicts the variation of slope, canopy, vegetation cover and undergrowth meanwhile figure 3 presents a comparison of indirect signs distribution with vegetation and with respect to elevation categories respectively.

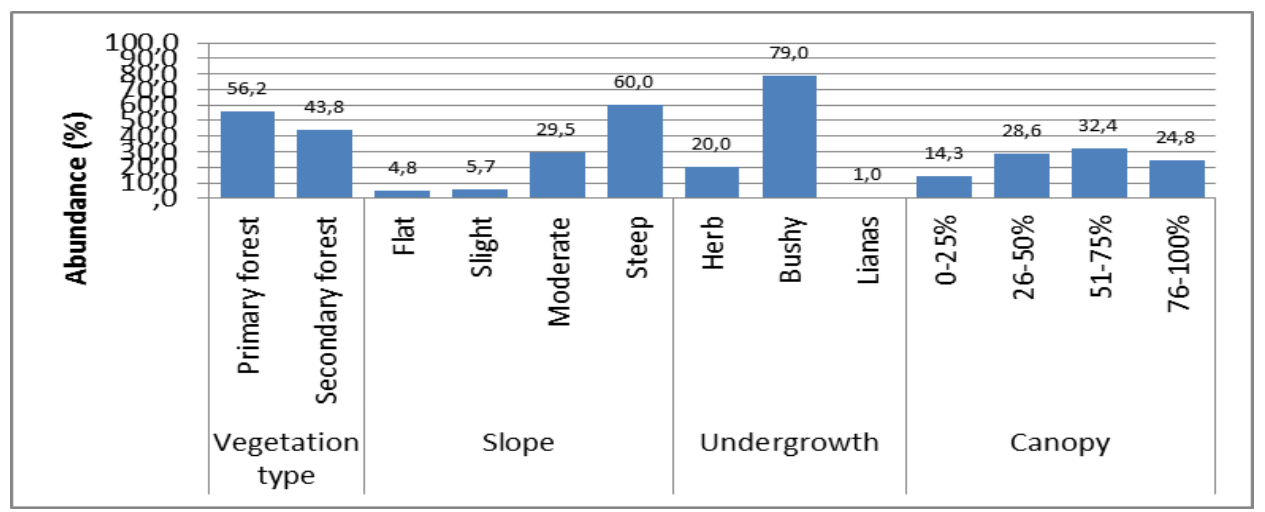

Figure 2. Variation of slope, canopy, vegetation type and undergrowth only for CRGs at the THWS 


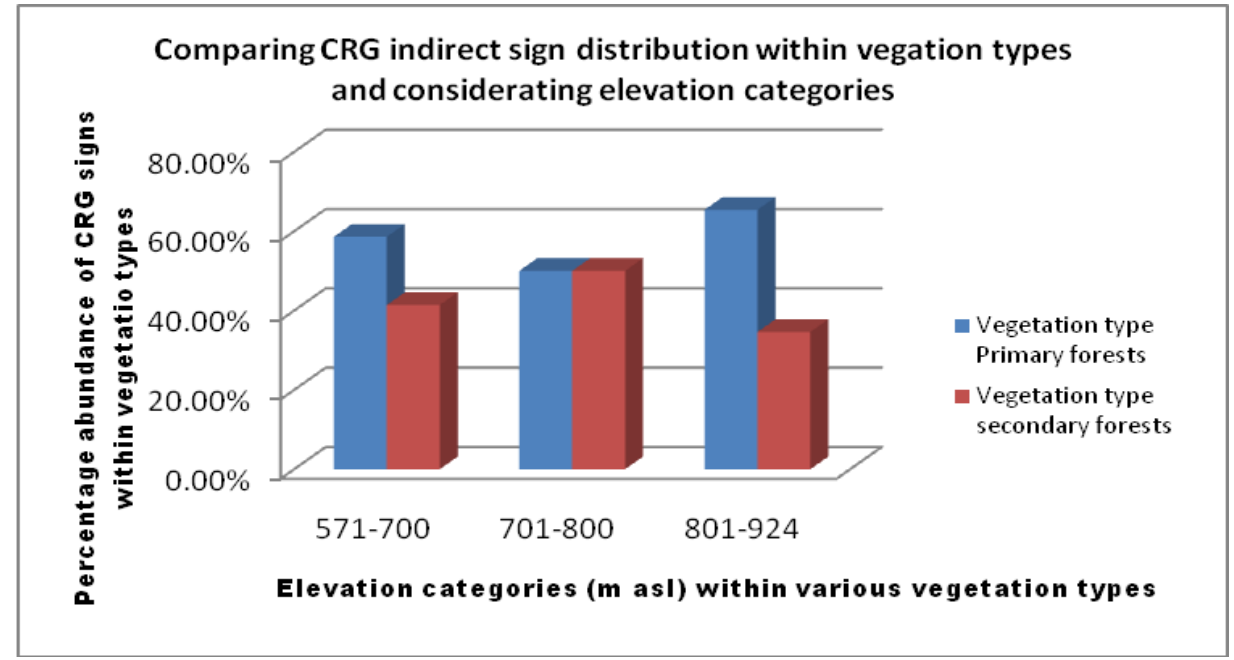

Figure 3. Comparison of indirect signs distribution with vegetation with respect to elevation categories

Fecal analysis and data collected on trails also provided an insight into the fruit food species consumed by THWS CRGs. Afromomum sp. recorded highest count of 700, Musa sp.seconded (178), Landolphia sp. (71), Ant mount (60), Marantacea sp. (20), Myranthus arboreus (20), Elaeis guineensis (17), Kola lipidota (15), Pseudospondias sp. (8), Unknown fruit (8), Bush Plum (3), Pith (3), Prunus avium (2), and unknown leaves (1).

Out of the 19 fecal samples collected, $47.4 \%(n=9)$ were collected at a range between $(701-$ $800 \mathrm{~m}$ asl). CRG species sign distribution was greater at altitudinal ranges between $701-800 \mathrm{~m}$ asl and the Cramer's $\mathrm{V}$ test $(\mathrm{V}=0.219, \mathrm{P}=0.600)$ revealed that there is a weak and non-significant level of association between altitudinal variations observed in this study and species sign occurrence.

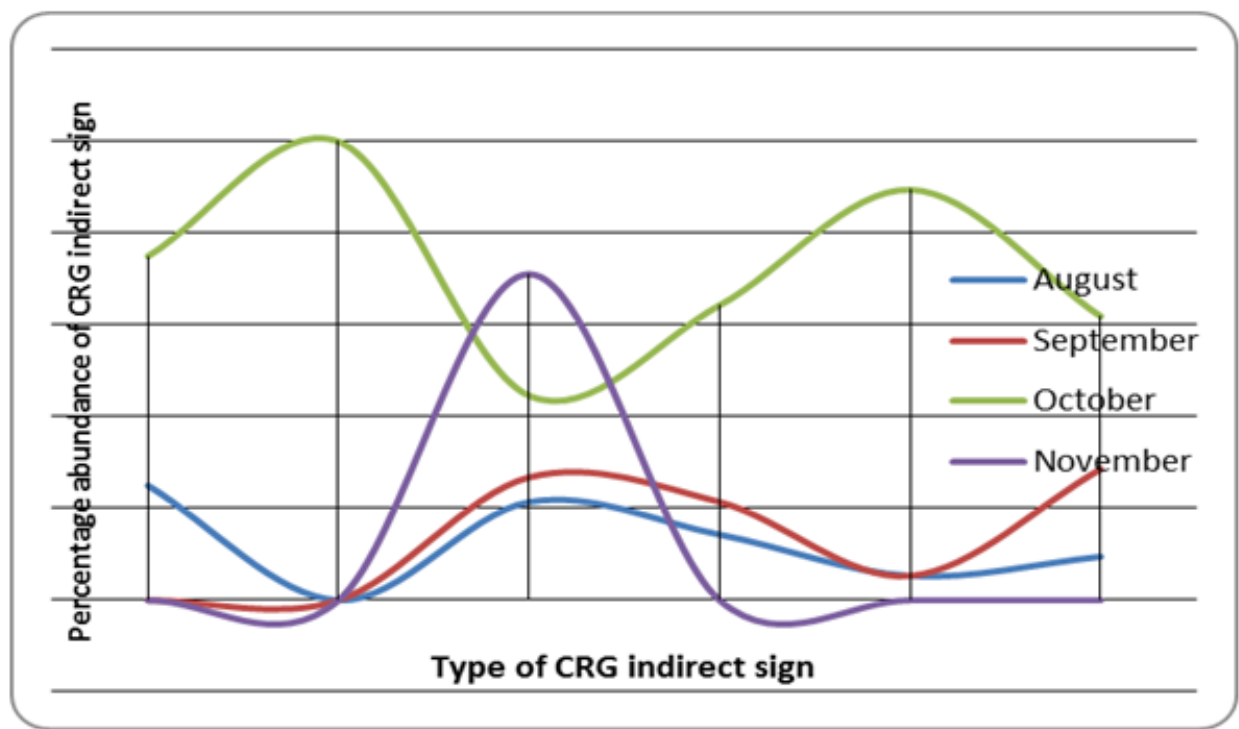

Figure 4. CRG percentage abundance of indirect signs observed per month at THWS during study period 


\section{I Macrothink}

\subsection{Measurement of CRG Insectivory}

Nineteen fecal samples were collected over the study period at the THWS area. Out of these, 3 were recent (i.e. 5>days old $>3$ ) meanwhile 16 were fresh (<3days old). Fresh dung was confirmed by the presence of gorilla footprints track leading to dung pile. The sample size obtained was due to the very difficult nature of the terrain, and the very small number of estimated CRG ( 25) within the sanctuary total area of 8087 ha (Nkembi et al., 2010). This culminated to very challenging physical difficulties in locating and following gorilla tracks. Bolus sizes of fecal samples varied between $2 \mathrm{~cm}$ and $7.5 \mathrm{~cm}$, with the mean being $5.5 \mathrm{~cm}$ and the median $5.0 \mathrm{~cm}$.

Findings at the THWS revealed that insects constitute the diet of CRG given that insect parts were noted in $73.7 \%(n=14)$ of the feces bolus collected, with $68.4 \%(n=13)$ of the fecal samples contained heads, 63.2\% $(\mathrm{n}=12)$ legs and $73.7 \%(\mathrm{n}=14)$ other insect parts. Main species identified included; Dorylus ant, Macrotermes sp., and Cubitermes sp.

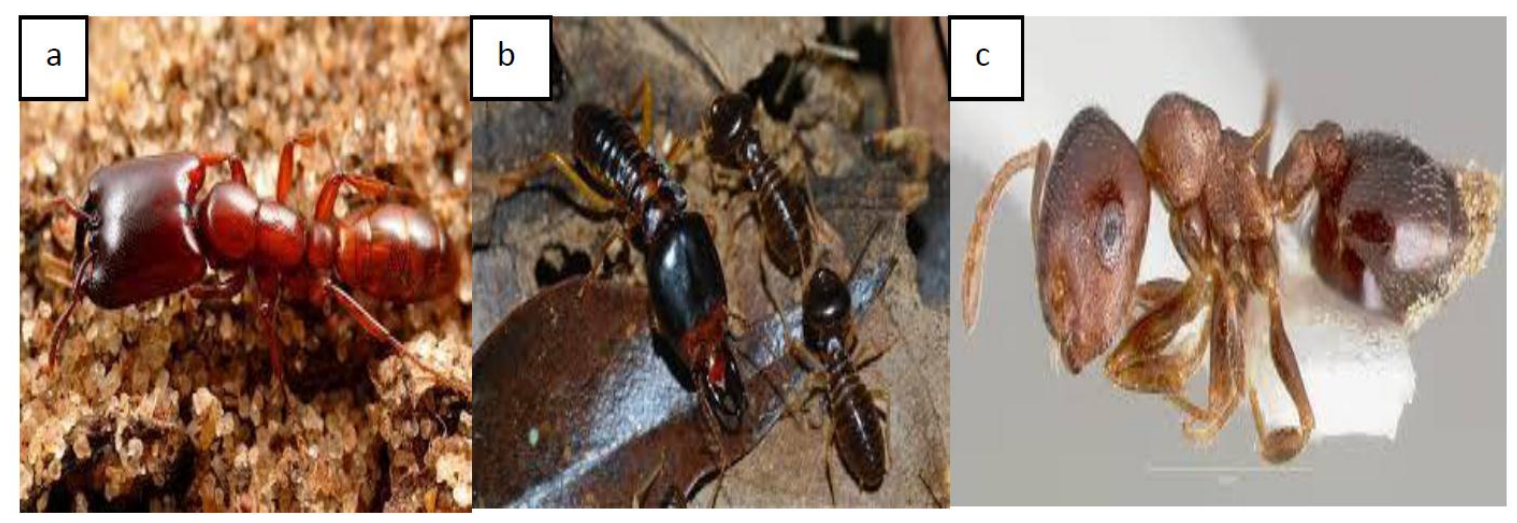

Figure 5. a) Dorylus ant, b) Macrotermes sp. insects and c) Cubitermes $s p$ 


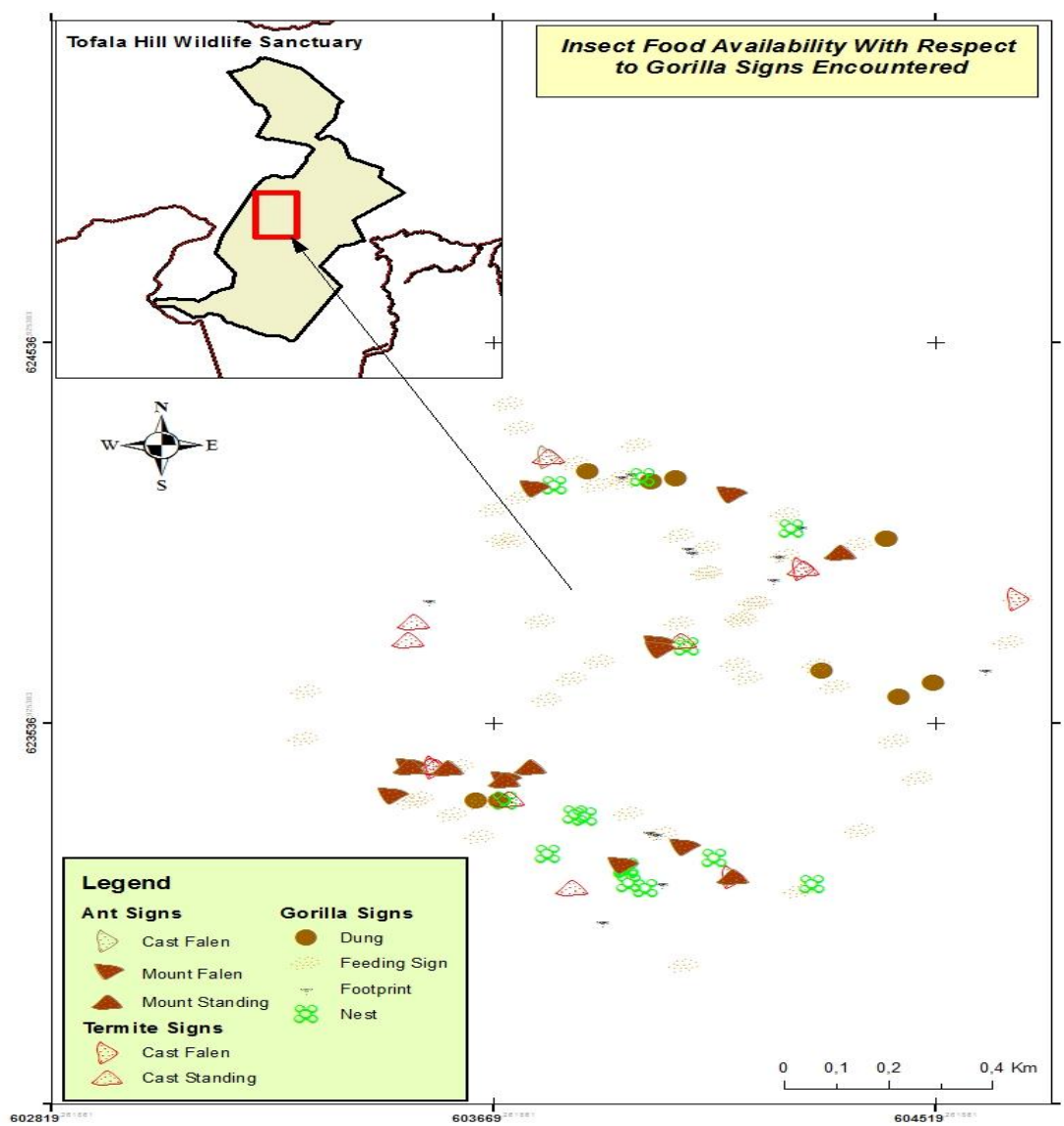

Figure 6. Insect food signs distribution at the THWS and identified insect feeding evidence

\subsection{Relationship between Age Class and Insect Feeding Habits in THWS CRG}

Insect parts were present in $75 \%(\mathrm{n}=9)$ of adult Gorilla dung, 50\% $(\mathrm{n}=1)$ of infant gorilla dung and $80 \%(\mathrm{n}=4)$ of juvenile individuals. Grouping infant and juvenile, it added to $71.4 \%$ $(n=7)$ of them. The table below summarizes the outcome of analysis;

Table 1. Association between presence of insect parts in the feces and Gorilla age

\begin{tabular}{|l|l|l|l|l|l|}
\hline \multicolumn{2}{|c|}{} & \multicolumn{2}{|l|}{ Insect part present? } & \multirow{2}{*}{ Total } \\
\cline { 3 - 6 } \multicolumn{2}{c|}{} & No & Yes & \\
\hline \multirow{3}{*}{ Comments } & \multirow{2}{*}{ Adult } & $\mathrm{n}$ & 3 & 9 & 12 \\
\cline { 3 - 6 } & & $\%$ & $25.0 \%$ & $75.0 \%$ & $100.0 \%$ \\
\cline { 3 - 6 } & \multirow{2}{*}{ Infant } & $\mathrm{n}$ & 1 & 1 & 2 \\
\cline { 3 - 6 } & & $\%$ & $50.0 \%$ & $50.0 \%$ & $100.0 \%$ \\
\cline { 3 - 6 } & \multirow{2}{*}{ Juvenile } & $\mathrm{n}$ & 1 & 4 & 5 \\
\cline { 3 - 6 } & & $\%$ & $20.0 \%$ & $80.0 \%$ & $100.0 \%$ \\
\hline Total & $\mathrm{n}$ & 5 & 14 & 19 & $\mathrm{n}$ \\
\hline & $\%$ & $26.3 \%$ & $73.7 \%$ & $100.0 \%$ & $\%$ \\
\hline
\end{tabular}

Cramer's V: V=0.191; $\mathrm{P}=0.707$ 


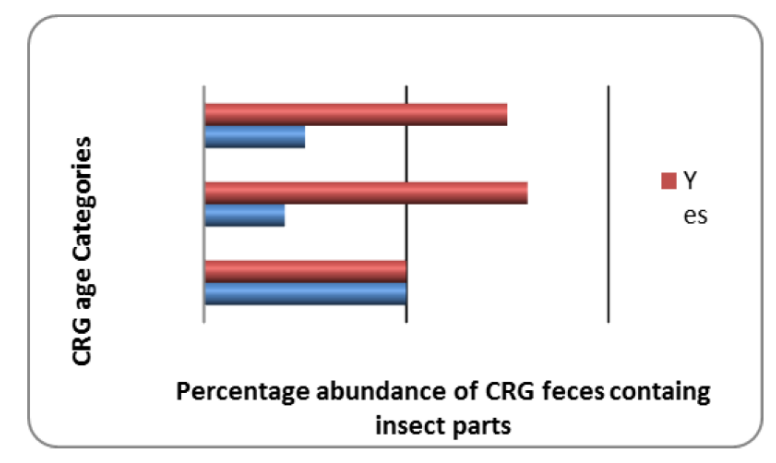

Figure 7. Presence of insect parts in infant, juvenile and adult gorillas at the THWS

Cramer's $\mathrm{V}$ test of association $(\mathrm{V}=0.191 ; \mathrm{P}=0.707)$ indicates that the difference in the quantity of insect parts recorded in various dung categories was not significant $(\mathrm{P}>0.05)$, therefore implying that insectivorous feeding habit of gorilla may be dependent on their age.

Data analysis using the spearman rho 2-tailed correlation test at 0.05 significant level revealed that there is a positive correlation between bolus size and age of gorilla and that bolus size increased significantly with age $(\mathrm{R}=0.489 ; \mathrm{P}=0.034)$. There is also a positive correlation between total number of insect parts and bolus size $(\mathrm{R}=0.439 ; \mathrm{P}=0.116)$ though not significant $(\mathrm{P}>0.05)$. The total number of insect parts counts increased with age as well $(\mathrm{R}=0.253$; $\mathrm{P}=0.383)$ though not significantly $(\mathrm{P}>0.05)$. These results show that there is an increasing preference to insectivory with $\mathrm{CRG}$ age though not very strong.

THWS CRGs feed on insects. Insect availability in the study site was measured with respect to the total distance covered for the trails tracked. There were 60 ant/insect mounts over an approximated distance covered of $96 \mathrm{~km}$. This made a density of 0.63 mounts $/ \mathrm{km}$.

\subsection{Altitudinal Influence on Insect Food Consumption by CRGs}

Fourteen of the nineteen fecal samples collected at the altitudinal range between $571-924 \mathrm{~m}$ asl presented insect parts. A total count of 1826 insect parts was found in all 14 samples containing insect parts. 68.4\% $(n=13)$ of the fecal samples contained heads, $63.2 \%(n=12)$ legs and $73.7 \%(n=14)$ other insect parts. Out of the fourteen samples, 4 were collected between altitudinal range of $571-700 \mathrm{~m}$ asl; 4 between $701-800 \mathrm{~m}$ asl and 6 between 801-924m asl.

The result from data analysis following Spearman's rho correlation coefficient indicates that there is a very weak negative and non-significant $(\mathrm{P}>0.05)$ correlation between altitude/elevation $(\mathrm{R}=-0.182 ; \mathrm{P}=0.533)$ and species abundance of $\mathrm{CRG}$ feces at the THWS. 


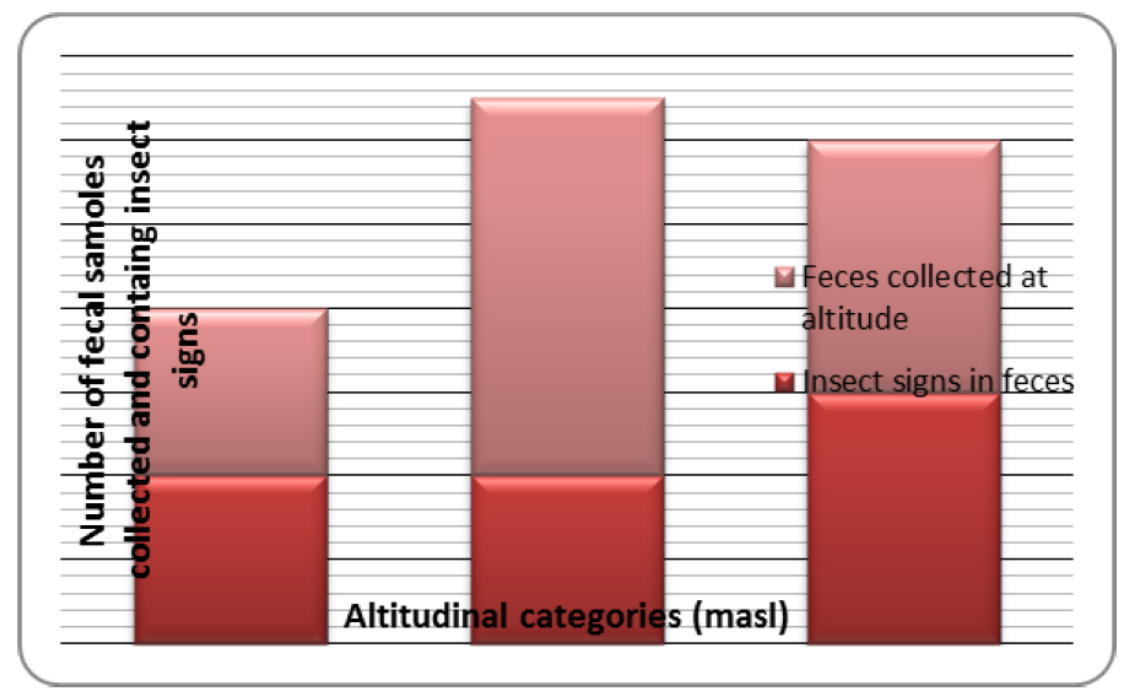

Figure 8. CRG fecal samples at various altitudinal ranges containing insect parts

\section{Discussions}

\subsection{Characterization of the CRG Habitat and Assessment of Food Availability}

CRG sign occurrence at the THWS was assessed taking into consideration insights on slope, altitude, vegetation type, and undergrowth type in order to characterize their habitats. Indirect sign (feeding, footprint, nests, etc), distribution with respect to altitude was equal in both primary and secondary forests $(50 \%$ each) characterized mostly by high altitudes of between $701-800 \mathrm{~m}$ asl. It could be concluded that the altitudinal range 701-800 masl is that with greatest CRG activity thus could also justify CRG habitat preference. Altitude did not also influence vegetation type within which indirect CRG signs were recorded.

The high occurrence of THWS CRG indirect signs at steep slopes was furthermore characterized by the presence of nests. These steep sites were noticed to be reused by THWS CRG species thus highlighting the fact that CRG preference to steep slopes may be a cause to frequent site reuse as the case of gorillas in the Mawambi hills (Etiendem, 2013). The case of Tofala is not different especially as there continues to be high human encroachment into CRG habitat forcing species to vacate to steep locations within their range.

Food was available throughout all four months of the study. However, the result from this study reveals no significant difference of food availability between the months and could however be considered to be biased given that no signs of specific foods were recorded in some months.

There exists variability in THWS CRGs dietary content. Similar to other documentations on gorillas, it was noticed that CRG move around breaking and chewing found food/fruits along their tracks. Afromomum sp. and Landolphia sp. are those species that were found to have a high frequency in gorilla trails. This could ascertain the conclusion of their preference to these two species (Deblauwe, 2006) whose abundance also is evident at altitudes between 700 and $900 \mathrm{~m}$ asl. This reveals the fact that altitudinal variations could have an influence on THWS CRG feeding habits and food availability patterns. This extrapolation is based on the 
frequency of occurrence of feeding signs (remnants especially) at various altitudinal ranges with abundance greatest between 701 to $800 \mathrm{~m}$ asl. The dietary variability in Mawambi hills and Afi CRG may be due to a lower elevation at Mawambi leading to greater plant diversity, as shown in studies aimed at investigating the dietary differences between western lowland and mountain gorillas (Yamagiwa et al. 1994; Ganas et al. 2008). Differences in the characteristic food availability pattern within CRG range sites including THWS could also be attributed to structural variation in forest composition and the history of anthropogenic disturbance (Sunderland et al. 2003; Willie et al. 2014).

\subsection{Investigation and Measurement of CRG Gorilla Insectivory}

The quantity of insects consumed by CRG could be assumed to be important especially as an important quantity was found in 14 fecal samples collected out of the 19, representing 1826 insect parts found. These results are a contrary to conclusions made by Etiendem (2013) and McFarland (2007) mentioning that CRGs at Mawambi hills and Afi Mountains had not exhibited any signs of insectivory.

The fact that insects were found in the diet of CRG at THWS during the rainy season could correlate with the point that Western lowland gorillas increase insect-eating in the rainy season, when fruit is abundant (Cipolletta et al., 2007; Doran et al., 2002). A few evidences of termite feeding were also recorded in THWS CRGs. Other studies explain that seasonality in termite-eating by gorillas was more complex and explained by different factors. This could not be assessed in this study especially as the study period covered just one season (rainy season). According to them, termite-eating by gorillas was positively influenced by the amount of succulent fruit in the diet but could also be by temporal availability of insect species. Our results support the finding of other studies that gorillas feed more on insects/termites during the rainy season when fruit is abundant (Doran et al., 2002). Given that this assertion was based on studies conducted on mostly mountain gorillas, the fact that CRG live in higher elevations makes the reason for their feeding habit to also be different.

Deblauwe (2006) explains that soil feeding termites might also be consumed for antidiarrheal purposes although this still needs to be investigated for certainty. According to Schaller (2003), increased consumption in Afromomum sp. could lead to diarrhea in gorillas. Afromomum $s p$. is used as a laxative in Congo hence explaining such characteristic. Termites could also provide significant amounts of iron, although at Bai Hokou (CAR) bioavailability of micronutrients in ripe fruits is predicted to be higher than in leaves (Milton, 2003).

\subsection{Relationship between Age Class and Insectivorous Feeding Habits in CRG.}

The content of insect parts in dung samples was however not evident for all the dungs collected nor for the various categories. Data analysis showed that a greater percentage of insect parts were found in adult feces $(5.5-7.2 \mathrm{~cm}$ bolus diameter). The difference (at $\mathrm{P}>0.05$ ) observed in the content of various categories using Cramer's V test of association ( $\mathrm{V}=0.191$; $\mathrm{P}=0.707$ ) implied that insectivorous feeding habit of THWS CRGs may be dependent on their age. In other words, gorilla feeding on insects could be associated to their age. This association seemed to be moderately strong. 
Gorillas generally feed on insects and this is revealed to be the case of THWS CRGs. Insect availability in the study site was measured with respect to the total distance covered for the trails tracked. There were 60 ant/insect mounts over an approximated distance covered of $96 \mathrm{~km}$. Although this result could not be considered representative, general observations made could conclude an abundance in termite casts and ant mounts in the survey site during the study period (rainy season). Moisture availability appears to stimulate aboveground foraging activity and insect species density, but heavy rain can decrease it (Kaspari \& Weiser, 2000; Levings, 1983). Rainforest sites on Barro Colorado Island (BCI) in Panama (Levings, 1983) and in Brazil (Coelho \& Ribeiro, 2006) had higher litter ant species densities in wet seasons compared to dry seasons.

\subsection{Investigation on Altitudinal Influence in the Consumption of Insect Food by CRGs}

Based on data analysis, THWS CRG insect feeding habit could decrease with altitude. The fact that the level of correlation is very weak and negative caused us to consider that altitudinal variation may not affect insectivorous habits in gorillas. This is supportive to Ganas and Robbins (2004) who mentioned that it seems insect-eating by gorillas is dependent on availability in relation to altitude. In other words, gorillas will feed on insects whenever it is available no matter the altitude. However, insect availability could be influenced by altitude based on variability in environmental conditions the higher you go. The high score in insect parts at the highest altitudinal range (701-800) could suggest prevailing insect quantities in the habitat. To fully explain the seasonality of insect-eating by great apes, local availability of prey must be measured (Ganas \& Robbins, 2004; Tutin \& Fernandez, 1992) and this could also hold for altitudinal differences within gorilla habitats as well. Mountain gorillas and CRG which inhabit mostly highland forests of Cameroon and Nigeria live at higher altitudes than lowland gorillas where fruit tree densities are low (Ganas et al., 2008). Fruit tree scarcity could also be attributed to CRG consumption of insects in the THWS area. CRGs occupy various range habitats including lowland riparian forests and high altitude grasslands for THWS and at $>1800 \mathrm{~m}$ asl for Kagwene), this variation in altitude as well as vegetation type justifies population differences in feeding and ranging habits (Oates et al., 2003).

\section{Conclusion}

This study served to make conclusions on investigations and uncertainty in insectivory in CRGs at the THWS particularly and across its habitat range in general. The findings permit us to make the first assertion on CRG insectivorous feeding habit. It also permits us to confirm the research hypothesis earlier adopted "there exists no altitudinal influence on Cross River gorilla insectivory". Furthermore, given that insect parts were found in feces collected, it indicated that abundance of insect parts in feces was not necessarily dependent on altitude and was not also dependent on age. This therefore implies that insectivory is a determinant to habitat suitability in Cross River gorillas; in the other sense, CRG naturally feed on insects. The fact that insect species occurrence in gorilla feces is significant at all altitude, shows that insects are present at all altitudes. 


\section{Acknowledgement}

We want to acknowledge the technical support offered by the Environment and Rural Development Foundation (ERuDeF) and the Resource Center for Environment and Sustainable Development (RCESD). We also want to thank IDEA WILD for the equipment support as well as laboratories of IRAD Ekona and libraries of ERuDeF, RCESD, \& the Department of Forestry (University of Dschang).

\section{References}

Caldecott, J., \& Ferris S. (2005b). Gorilla overview. In: Caldecott J, Miles L, editors. World atlas of Great Apes and their conservation. Berkeley: University of California Press. p. 97-103.

Cipolletta, C., Spagnolietti, N., Todd, A., Robbins, M. M., Cohen, H., \& Pacyna, S. (2007). Termite feeding by Gorilla gorilla gorilla at Bai Hokou, Central African Republic. Int J Primatol., 28, 457-476. https://doi.org/10.1007/s10764-007-9129-5

Coelho, I. R., \& Ribeiro, S. P. (2006). Environment heterogeneity and seasonal effects in ground-dwelling ant (Hymenoptera: Formicidae) assemblages in the Parque Estadual do Rio Doce, MG, Brazil. Neotropical Entomology, 35(1), 19-29.

https://doi.org/10.1590/S1519-566X2006000100004

Deblauwe, I. (2006). How insectivorous are gorillas?. Gorilla J., 33, 20-21.

Deblauwe, I., Dupain, J., Ngeunang, G. M., \& Werdenich, D. (2003). Insectivory by Gorilla gorilla gorilla in southeast Cameroon. Int. J.Primatol., 24, 493-502.

https://doi.org/10.1023/A:1023732212408

Doran, D. M., Mcneilage, A., Greer, D., Bocian, C., Mehlman, P., \& Shah, N. (2002). Western lowland gorilla diet and resource availability: New evidence, cross-site comparisons, and reflections on indirect sampling methods. American Journal of Primatology, 58(3), 91-116. https://doi.org/10.1002/ajp.10053

Doran-Sheehy, D. M., Shah, N. F., \& Heimbauer, L. A. (2006). Sympatric western gorilla and mangabey diet: re-examination of ape and monkey foraging strategies. In G. Hohmann, and M. M. Robbins (Eds.), Feeding ecology in apes and other primates: Ecological, Physical and Behavioral Aspects (Vol. 48, pp. 49). Cambridge University Press.

Etiendem, D. N., \& Tagg, N. (2013). Feeding Ecology of Cross River Gorillas (Gorilla gorilla diehli) at Mawambi Hills: The Influence of Resource Seasonality. International Journal of Primatology, 34(6), 1261-1280. https://doi.org/10.1007/s10764-013-9739-z

Etiendem, D. N., Funwi-Gabga, N., Tagg, N., Hens, L., \& Indah, E. K. (2013). The Cross River Gorillas (Gorilla gorilla diehli) at Mawambi Hills, South-West Cameroon: Habitat Suitability and Vulnerability to Anthropogenic Disturbance. Folia Primatologica, 84(1), 18-31. https://doi.org/10.1159/000345853

Foraging profiles of sympatric lowland gorillas and chimpanzees in the Lopé Reserve, Gabon. 
(1991). Philosophical Transactions of the Royal Society of London. Series B: Biological Sciences, 334(1270), 179-186.

Fossey, D., \& Harcourt, A. (1977). Feeding Ecology of Free-ranging Mountain Gorilla (Gorilla gorilla beringei). Primate Ecology: Studies of Feeding and Ranging Behavior in Lemurs, Monkey and Apes, 415-447. https://doi.org/10.1016/B978-0-12-176850-8.50019-6

Ganas, J., \& Robbins, M. M. (2004). Intrapopulation differences in ant eating in the mountain gorillas of Bwindi Impenetrable National Park, Uganda. Primates, 45(4), 275-278.

https://doi.org/10.1007/s10329-004-0089-5

Ganas, J., Ortmann, S., \& Robbins, M. M. (2008). Food preferences of wild mountain gorillas. American Journal of Primatology, 70(10), 927-938.

https://doi.org/10.1002/ajp.20584

Gartlan, S. (1989). La Conservation des Écosystèmes Forestiers du Cameroun. IUCN, Gland, Switzerland.

Harvey, Y., Tchiengue, B., \& Cheek, M. (2010). The Plants of Lebialem highlands (Bechati-Fossimondi-Besali forest). Royal Botanic Gardens, Kew, UK

Kaspari, M., \& Weiser, M. D. (2000). Ant Activity along Moisture Gradients in a Neotropical Forest1. Biotropica, 32(4), 703.

https://doi.org/10.1646/0006-3606(2000)032[0703:AAAMGI]2.0.CO;2

Kühl, H., Maisels, F., Ancrenaz, M., \& Williamson, E. (2008). Best practice guidelines for surveys and monitoring of great ape populations.

Levings, S. C. (1983). Seasonal, Annual, and Among-site Variation in the Ground Ant Community of a Deciduous Tropical Forest: Some Causes of Patchy Species Distributions. Ecological Monographs, 53(4), 435-455. https://doi.org/10.2307/1942647

McFarland, K. L. (2007). Ecology of Cross River Gorillas (Gorilla gorilla diehli) on Afi Mountain, Cross River State, Nigeria. Ph.D. Thesis, Graduate Center, City University of New York, New York.

Mcgrew, W. C. (2014). The 'other faunivory' revisited: Insectivory in human and non-human primates and the evolution of human diet. Journal of Human Evolution, 71, 4-11.

https://doi.org/10.1016/j.jhevol.2013.07.016

McNeilage, A., Robbins, M., Gray, M., Olupot, W., Babaasa, D., Bitariho, R., ... Baker, J. (2006). Census of the mountain gorilla Gorilla beringei beringei population in Bwindi Impenetrable National Park, Uganda. Oryx, 40(4), 419-427.

https://doi.org/10.1017/S0030605306001311

Milton, K. (2003). The Critical Role Played by Animal Source Foods in Human (Homo) Evolution. The Journal of Nutrition, 133(11). https://doi.org/10.1093/jn/133.11.3886S

Nishihara, T. (1995). Feeding ecology of western lowland gorillas in the Nouabalé-Ndoki National Park, Congo. Primates, 36(2), 151-168. https://doi.org/10.1007/BF02381342 


\section{Ml Macrothink}

Environmental Management and Sustainable Development

ISSN 2164-7682

2019, Vol. 8, No. 2

Nishihara, T., \& Kuroda, S. (1991). Soil-Scratching Behaviour hy Western Lowland Gorillas. Folia Primatologica, 57(1), 48-51. https://doi.org/10.1159/000156564

Nkembi, L., Nkemnyi, M. F., \& Alongamoh, E. (2008). The Status and Distribution of Cross River gorillas in the Lebialem-Mone Forest Landscape, SW Cameroon. Final Report submitted to WorldWide Fund for Nature, Regional Office, Yaounde, Cameroon ERuDeF, Buea, Cameroon.

Nkemnyi, F. M., Koedam, N., \& Rik, D. V. (2011). Livelihood and Conservation:Reconciling community livelihood needs and conservation strategies in the Bechati Forest Area, Western Cameroon. LAP Lambert Academic Publishing, Saarbrucken, Germany.

Oates, J. F., Mcfarland, K. L., Groves, J. L., Bergl, R. A., Linder, J. M., \& Disotell, T. R. (2003). The Cross River gorilla: Natural history and status of a neglected and critically endangered subspecies. Gorilla Biology, 472-497.

https://doi.org/10.1017/CBO9780511542558.021

Plumptre, A. J. (2009). The chemical composition of montane plants and its influence on the diet of the large mammalian herbivores in the Pare National des Volcans, Rwanda. Journal of Zoology, 235(2), 323-337. https://doi.org/10.1111/j.1469-7998.1995.tb05148.x

Remis, M. J. (1997). Western lowland gorillas (Gorilla gorilla gorilla) as seasonal frugivores: Use of variable resources. American Journal of Primatology, 43(2), 87-109. https://doi.org/10.1002/(SICI)1098-2345(1997)43:2<87::AID-AJP1>3.0.CO;2-T

Remis, M. J. (1999). Tree structure and sex differences in arboreality among western lowland gorillas (Gorilla gorilla gorilla) at Bai Hokou, Central African Republic. Primates,40(2), 383-396. https://doi.org/10.1007/BF02557560

Robbins, M. M. (2007). Gorillas Diversity in ecology and behavior. In: Campbell CJ, Fuentes A, Mackinnon KC, Panger M, Bearder SK, editors. Primates in perspective. Oxford: Oxford University Press. p. 305-321.

Rogers, M. E., Abernethy, K., Bermejo, M., Cipolletta, C., Doran, D., Mcfarland, K., ... Tutin, C. E. (2004). Western gorilla diet: A synthesis from six sites. American Journal of Primatology, 64(2), 173-192. https://doi.org/10.1002/ajp.20071

Sunderland-Groves, J. L., Maisels, F., \& Ekinde, A. (2003). Surveys of the Cross River gorilla and chimpanzee populations in Takamanda Forest Reserve, Cameroon.

Sanz, C., \& Morgan, D. (2007). Chimpanzee tool technology in the Goualougo Triangle, Republic of Congo. Journal of Human Evolution, 52(4), 420-433.

https://doi.org/10.1016/j.jhevol.2006.11.001

Schaller, G. B. (1963). Mountain Gorilla. PsycEXTRA Dataset.

Stanford, C. B. (2005). The behavioral ecology of sympatric African apes: Implications for understanding fossil hominoid ecology. Primates, 47(1), 91-101.

https://doi.org/10.1007/s10329-005-0148-6 


\section{Macrothink}

Stanford, C. B. (2008). Hohmann, Robbins, and Boesch — Feeding ecology in apes and other primates Feeding ecology in apes and other primates. Cambridge Studies in Biological and Evolutionary Anthropology 48 Hohmann Gottfried Martha M. Robbins Christoph. Boesch editors. 2006 New York Cambridge University Press xvi 523. Ecology, 89(2), 591-592. https://doi.org/10.1890/BR08-10.1

Sunderland-Groves, J. L., Ekinde, A., \& Mboh, H. (2009). Nesting Behavior of Gorilla gorilla diehli at Kagwene Mountain, Cameroon: Implications for Assessing Group Size and Density. International Journal of Primatology, 30(2), 253-266.

https://doi.org/10.1007/s10764-009-9340-7

Tutin, C. E., \& Fernandez, M. (1992). Insect-eating by sympatric Lowland gorillas (Gorilla g. gorilla) and chimpanzees (Pan t. troglodytes) in the Lopé Reserve, Gabon. American Journal of Primatology, 28(1), 29-40. https://doi.org/10.1002/ajp.1350280103

Tutin, C. E., \& Fernandez, M. (1993). Faecal Analysis as a Method of Describing Diets of Apes: Examples from Sympatric Gorillas and Chimpanzees at Lope, Gabon. Tropics, 2(4), 189-197. https://doi.org/10.3759/tropics.2.189

Willie, J., Tagg, N., Petre, C., Pereboom, Z., \& Lens, L. (2013). Plant selection for nest building by western lowland gorillas in Cameroon. Primates, 55(1), 41-49.

https://doi.org/10.1007/s10329-013-0363-5

World atlas of great apes and their conservation. (2006). Choice Reviews Online, 43(06).

Yamagiwa, J., Maruhashi, T., Yumoto, T., Mwanza, N., Goodall, J., \& Itani, J. (n.d.). Dietary and ranging overlap in sympatric gorillas and chimpanzees in Kahuzi-Biega National Park, ZaïreDietary and ranging overlap in sympatric gorillas and chimpanzees in Kahuzi-Biega National Park, Zaïre. Great Ape Societies, 82-98.

Yamagiwa, J., Mwanza, N., Yumoto, T., \& Maruhashi, T. (1991). Ant eating by eastern lowland gorillas. Primates, 32(2), 247-253. https://doi.org/10.1007/BF02381183

Yamagiwa, J., Mwanza, N., Yumoto, T., \& Maruhashi, T. (1994). Seasonal change in the composition of the diet of eastern lowland gorillas. Primates, 35(1), 1-14. https://doi.org/10.1007/BF02381481

\section{Copyright Disclaimer}

Copyright for this article is retained by the author(s), with first publication rights granted to the journal.

This is an open-access article distributed under the terms and conditions of the Creative Commons Attribution license (http://creativecommons.org/licenses/by/3.0/). 